\title{
ПОЛЬСКИЙ ЯЗЫК
}

УДК 81.119+811.162.1

DOI 10.23951/1609-624X-2017-11-104-109

\section{AССОЦИАТИВНЫЕ СВЯЗИ КОНЦЕПTА «ŚMIERĆ»"}

\author{
Н. В. Деева
}

Кемеровский государственный институт культуры, Кемерово

\begin{abstract}
Рассматриваются ассоциативные связи польского концепта «śmierć», исследование которых может помочь при моделирования его структуры. На уровне вербальных ассоциаций установлено, что в сознании носителей языка понятие «śmierć» включает в себя признаки 'конца', 'ухода', а также 'новой/лучшей жизни' и др. В ассоциативные ряды включаются не только тематически связанные единицы (śmierć - cmentarz, pogrzeb и т. д.), но и единицы, репрезентирующие визуализированный образ смерти, ее атрибуты (kobieta, szkielet, kosa, miecz и т. д.), описательно выражающие отношение к ней, дающие ей оценку (chtód, ciemność). Индивидуальные (неповторяющиеся) ассоциаты позволяют увидеть направления расширения ассоциативных связей анализируемого концепта и специфику личностного осмысления того, что такое смерть.
\end{abstract}

Ключевые слова: концепт, репрезентащия концепта, вербальные ассощиации, польская лингвокультура.

Изучение концептов, моделирование и описание их структуры привлекают к себе внимание многих современных лингвистов, «поскольку дают возможность установить способы языкового осмысления действительности и выявить приоритетные ценности в коллективной и индивидуальной картинах мира» [1, с. 23]. Как сложное ментальное образование концепт репрезентируется совокупностью языковых средств (лексем, фразеологизмов, свободных сочетаний, текстов и т. д.). Так, в польском языке основными лексическими репрезентантами концепта «śmierć» («смерть») выступают следующие единицы: śmierć, zgon, zejście [2, c. 206]. С понятийной точки зрения смерть в польской лингвокультуре мыслится как «koniec życia człowieka lub zwierzęcia»/«кконец жизни человека или животного», что закреплено в первичном значении лексемы «śmierć» [3]. Под первичным в данном случае понимается значение, стоящее первым в словарной статье. Далее следуют значения с пометами «медицинское», «культурологическое», «книжное»: med. «ustanie procesów życiowych ogranizmu»/«прекращение процессов жизнедеятельности организма»; kultur. «wyobrażenie postaci, przedstawianej najczęściej jako szkielet z kosą, której przypisuje się powodowanie śmierci -końca życia człowieka»/«изображение фигуры, чаще всего представляемой как скелет с косой, которой приписывается предсказание смерти - конца жизни человека»; książk. «sytuacja, w której coś przestaje istnieć lub przestaje być używanе»/«ситуация, в которой что-то перестает существовать или прекращает использоваться» [3]. Подобное перераспределение значений от более кон- кретного (или близкого самому человеку) «конец жизни» через более общее (или точное, научное) медицинское к переносному «конец чего-либо вообще» в структуре полисемантического номинатива «śmierć» отражает логику национального мировидения. Для сравнения: в толковых словарях русского языка первичным у лексемы «смерть» выступает значение - «прекращение жизнедеятельности организма», а вторичным - «конец, полное прекращение какой-нибудь деятельности» [4, с. 724].

Лексема zgon, являясь стилистически маркированной, еще более специализирована по своему значению - urzęd. «koniec życia człowieka» / офиц. «конец жизни человека» [3]. В своем вторичном значении (книжном, медицинском) лексема zejście обозначает «смерть», «кончину».

Таким образом, основным понятийным признаком в структуре концепта «śmierć» выступает признак 'конец/прекращение'.

В структуру анализируемого концепта входят и образные признаки («śmierć - sen», «śmierć - ptak», «śmierć - choroba» и др.), в основе которых лежит метафорический перенос (подробнее см. [5]).

Анализ признаков, формирующих структуру того или иного концепта, не может быть полным без исследования его ассоциативно-культурного фона. Как отмечает Ю. Н. Караулов в предисловии к «Русскому ассоциативному словарю», «любое слово в нашем сознании, в памяти, точно так же, как в речевой цепи, не существует $<\ldots>$ в отдельности: оно десятками, сотнями „нитей“ тянется к другим словам...» (цит. по [6]), следовательно, и любое понятие не существует изолировано, его 
связь с другими понятиями (концептами) позволяет выявить особенности бытования конкретного понятия (концепта) в сознании носителей языка, установить его национальную специфику.

Среди слов-реакций, полученных в результате свободного ассоциативного эксперимента и опросов на польскоязычных форумах «Zapytaj.pl» и «Cmentarium» (в период с 2011 по 2016 г.) на словостимул «śmierć» отмечены единицы, представляющие собой образные репрезентации смерти (szkielet, młoda kobieta и др.), дескриптивные (koniec, kres и др.) и оценочные (ciemność, przerażenie и под.).

Образно смерть носителями польского языка представляется как ангел (aniol), тень (cień), чернота (cierń), белая фигура без атрибутов (biała postać bez żadnego atrybutu), скелет (szkielet). Caмым частотным в ответах респондентов оказался образ женщины в белом или черном (46,6% опрошенных указали эту ассоциацию со словом «śmierć»). Данный персонифицированный образ смерти своими корнями уходит в далекое прошлое: в польской мифологии существует богиня Марена (польск. Marzanna), олицетворяющая собой смерть и зиму. Имя этой богини является производным от праиндоевропейского корня *mar-/*mor-, означающего 'смерть'. В позднем Средневековье сложилась традиция изображения смерти в произведениях искусства как женщины с косой. Б. Огродовска в своей книге, посвященной польским традициям и семейным обычаям, описывает смерть в образе женщины следующим образом: «...wysoka, chuda i blada kobieta z trupią czaszką zamiast głowy... zawsze z nieodłącznym swym atrybutem, wielką kosą» [7, c. 232]. Мифологический и средневековый образы смерти оказались настолько устойчивыми, что и для современных представителей польской лингвокультуры являются основными в ассоциациях. При этом некоторые респонденты конкретизировали смерть в образе женщины: dtugie blond wtosy, skóra biała jak papier, czarne oczy; jest $w$ czarnym poszarpanym płaszczu, ma czarne oczy $i$ kościste palce; po prostu Lady of Chaos; ma bose nogi; zielone oczy, rude włosy. Поскольку смерть, «к которой все живое приговорено законами эволюции, может переживаться человеком только как нечто индивидуально-личностное» [8, с. 85], постольку и многолик этот ее женский образ: у кого-то смерть имеет зеленые глаза и рыжие волосы, у кого-то - длинные светлые волосы и белую, как бумага, кожу и т. д. Общим в десяти описаниях смерти в облике женщины оказался цвет ее глаз - черный. Этот цвет в славянской культуре искони ассоциировался с землей, мраком и смертью, отсюда и однотипность определений.

Однако смерть может иметь не только женское лицо: 13,4 \% респондентов в качестве слова-реак- ции на слово-стимул «śmierć» указали лексему kosiarz/кocapb, чаще с определением или дополнением mroczny kosiarz или kosiarz śmierci. Примечательно, что лексема «śmierć» как репрезентация одноименного концепта в польском языке - это существительное женского рода, равно как и именаэвфемизмы: kostucha (разг. «курносая, о смерти»), kostusia, białokoścista, Zośka (диал.), Jadwisia (диал.). Сочетаемость лексемы «śmierć» с именами типа «matula» (мамуля), «kuma» (кума), «babula» (бабуля) также указывает на ее принадлежность в наивной картине мира носителей польского языка к женскому полу: Do tona swego przytuli każdego wśród nas - nie ujdziesz śmierci-babuli, zawita na czas (Narodowy Fotokorpus Języka Polskiego). Но среди диалектных лексем для номинации смерти существует и номинатив мужского рода - kostecki, используемый в устойчивом выражении kostecki do kogoś przyszedt (ср.: pус. кондрашка хватил).

Как отмечалось выше, неизменным атрибутом смерти, персонифицированной в образе женщины, выступает коса, среди атрибутов смерти в словахреакциях респондентов, помимо косы, отмечены следующие единицы: skrzydta/крылья, klepsydra/ песочные часы, mіесz/меч, krzyż ankh/крест-анкх, tuk $i$ strzały/лук и cmрельл. Лексема «skrzydła» как реакция на слово-стимул, возможно, возникает в связи с ассоциацией смерти с ангелом. Лук как атрибут смерти встречается, наряду с косой, уже в средневековой иконографии. Меч представляет собой, пожалуй, более современную интерпретацию того оружия, которое может находиться в руках у разящей смерти. Поскольку смерть - это конечная точка в существовании (прекращение течения времени для живущего), то наличие в этом ряду лексемы «klepsydra» вполне закономерно. Заслуживает внимания упоминание в ассоциативном ряду такой лексемы как $k r z y \dot{z}$ ankh/кресm-aнкx. В целом крест является одним из древнейших сакральных знаков, у славян наряду с прочими значениями и функциями «выступает как один из основных знаков погребальной обрядности; в народных верованиях фигурирует как символ смерти» [9, с. 652]. Что же касается креста-анкх, то это египетский символ, так называемый «крест бессмертия», который «часто ассоциируют с вечной жизнью, процессами перерождения, цикличностью мироздания» [10], потому появление этой лексемы в ряду слов-реакций на слово-стимул «śmierć» у 6,3\% респондентов столь интересно.

Единично представлены такие образные репрезентации смерти, как zdmuchnięty płomień świecy/ задутое пламя свечи (речь, вероятнее всего, здесь идет о прекращении жизни, символом которой и является огонь) и głęboki sen/2лубокий сон, zaśnięcie/зacblnaнuе. Примечательно, что метафора 
«смерть - (вечный) сон», являясь довольно устойчивой и частотно встречаемой в произведениях художественной литературы (...że lekkim snem zakoncze zycie... A. Mickiewicz; Sen staje się smiercią. J. P. Krasnodębski), нашла столь незначительное отражение в словах-реакциях респондентов на слово-стимул «śmierć»».

По мнению Л. И. Ручиной, «материал ассоциативных экспериментов дает возможность выявить наибольшее количество актуальных для современного состояния сознания когнитивных признаков концепта» [11, с. 102]. Дескриптивные репрезентации представляют собой по сути определение понятия «śmierć», к ним можно отнести следующие слова-реакции: koniec/конеu, kres/конец, предел, konіес żусіа/конеи жизни, nieistnienie/несуществование. Носителями языка смерть описывается как некий процесс: oddzielenie duszy od ciała/oтделение души от тела, odjeście z tego świata/yход с этого cвета, odejście do tamtego świata/yход в иной мир, odejście od innych/yxод om ocmaльныхx. Данные реакции объективируют такие понятийные признаки анализируемого концепта, как «конец», «прекращение существования», «уход».

Религиозные представления о смерти как о переходе души умершего в лучший/иной мир, вера в возможность жизни после смерти также нашли свое отражение в ассоциативных рядах: nowe życie/ новая жизнь, lepsze żсіе/лучшая жизнь, сиdowniejsze życiе/более чудесная жизнь, nowy poczatek/ новое начало.

Сравнительно немногочисленно в ассоциациях оказались представлены слова, называющие объекты, реалии, связанные с обрядом погребения умершего: cmentarz/кладбище (6 единиц), pogrzeb/noxopoны (5 единиц), płacz (3 единицы), tomot kamieni o drewno/стук камней о дерево (1 единица), łóżko z rozwianym prześcieradtem/кровать с развивающчимся покрывалом (1 единица), chtód kaplicy/холод часовни (1 единица).

Несмотря на многовековой интерес человека к смерти, знания о последней до сих пор не являются полными, смерть часто осмысляется как неизвестность, пустота, что нашло свое отражение в ответах респондентов: pustka/nycmoma (30 единиц), піс/ничто (24 единицы), zapomnienie/забвение (5 единиц).

Отношение к смерти, ее оценка обнаруживаются в словах-реакциях, называющих чувства, которые испытывает человек, столкнувшись со смертью. Анализ полученных в результате опроса единиц показал, что чаще всего смерть ассоциируется с тяжелыми, неприятными чувствами или состояниями: smutek/nечаль, cierpienie/cmpaдание, przerażenie/cmpax, tęsknota/mоска, żałoba/cкорбь, strata/ утрата, depresja/dепрессия, bezład/paccтройство, utrata/noтеря. И только в 5 \% ответов смерть определяется как то, что дает человеку что-то положительное: wolność/свобода, kоniec cierpienia/конеи страданию, wybawienie od problemów/избавление от проблем, światło/cвет, ulga dla osoby umierajaсеј/облегчение для умирающего человека.

Негативное отношение к смерти представлено в ассоциациях последней с холодом, темнотой, развалинами и под.: chłód/холод, zimno/холодно, ciemność/mемнота, nieprzyjemny, chłodny oddech kogoś strasznego/неприятное холодное дыхание кого-то страшного, пос polarna na biegunie północпут/полярная ночь на северном полюсе, zариszczonе ogrody/запущенные cadbl, ruіпу/развалины, opuszczone domy / покинутые дома, wypalenie/вblгорание.

Оценочной является и ассоциация смерти с цветом. Еще у представителей примитивных культур (малазийских бушменов, австралийских аборигенов, африканских племен йоруба, догонов и др.) черный цвет ассоциировался со злом, смертью [12]. Среди представленных слов-реакций czarny kolor/черный ц̧вет упоминается 84 \% респондентов, поскольку черный - это цвет траура у поляковкатоликов, при чем иногда определение «черный» идет вместе с лексемой «серый» (czarny i szary kolor). И только один раз в ответах опрошенных встретилась лексема biel/белизна (так как данная лексема в ряду ассоциаций респондента идет после лексемы czystość/чucmoma, то, возможно, что эта индивидуальная ассоциация относится к представлениям о том/другом свете, в который человек попадает после смерти).

Из ряда звуковых ассоциаций самой многочисленной является cisza/muшина (отмечена 41 \% респондентов), которая по древним народным представлениям царит в загробном мире: «В потустороннем мире нет ни времени, ни календаря, ни света, ни жизни. Там царит полная тишина - не слышно лая собак, крика петухов, людских голосов, звона колоколов» $[13$, с. 186]. $28 \%$ респондентов указали как ассоциацию со смертью грустную музыку (smutna muzyka).

Безусловно, что выделенные частотные или повторяющиеся ассоциации отражают единый культурный, социальный опыт носителей польского языка и могут быть объяснены принадлежностью респондентов к единой этнической группе, что же касается ассоциаций единичных, то они не менее важны для анализа культурно-смыслового фона концепта «śmierć», поскольку отражают индивидуальный опыт осмысления такого явления, как смерть. Так, среди данного рода ассоциаций присутствуют единицы, понятийно связанные с религиозными (Bóg/бoг, wieczny spokój/вечныı̆ покой) или философскими (ostatni wybór/nocлед- 
ний выбор, podsuтожапіе żyсіа/подытоживание жизни) представлениями о смерти. Поскольку наступление смерти для живого организма характеризуется рядом физиологических проявлений, некоторые респонденты включают в ассоциативный ряд слов-реакций единицы, называющие эти проявления: rozktadanie się ciat/pазложение тел, bladość/бледность, cień w осzаch/тень в глазах, zwtoki/мертвое тело, plamy opadowe/mрупныье пятна.

Традиционно у славян кровь считается средоточием жизни, ее символом, однако включение лексемы krew в ассоциативный ряд номинатива śmierć, позволяет говорить о том, что для конкретного представителя польской лингвокультуры смерть осмысляется не только как некий естественный процесс, завершающий жизнь, но и как что-то насильственное (например, смерть в результате убийства).

Также смерть связывают со старостью, ветхостью (stary czlowiek/cтарый человек, stare i zniszczone ubrania/cтарая и изношенная одежда, zakurzone i wytarte ksiegi/nыльные и потертые книги), чем-то нереальным (fantastyka/фантастика) или, напротив, неизбежным (smutna rzeczywistość) грустная реальность), конкретным историческим периодом (średniowiecze/средневековье), чем-то ядовитым (gaz trujacy koloru zielonego/ядовитый газ зеленого ивета), бескрайним (odmęty wody/дословно: бездны воды, bezkresna przestrzeń/бесконечное пространство) и конкретным продуктом (śmietana/сметана).

В ряду индивидуальных ассоциаций отмечены и три варваризма (memento mori - лат. «помни о смерти», mors omnia aequat - лат. «для смерти все равныl», danse macabre - фран. «пляска смерти»), отражающие культурный опыт и знания конкретного носителя польского языка.

Таким образом, ассоциативный фон концепта «śmierć» формируется, с одной стороны, за счет культурной памяти носителей польского языка, о чем свидетельствуют слова-реакции из группы образных репрезентаций смерти (женщина в белом или черном одеянии, с косой или иным атрибутом, мужчина-косарь, скелет), с другой стороны, включает в себя понятийные признаки, закрепленные в структуре анализируемого концепта («конец», «уход»), а также признаки иных концептов, пересекающихся с концептом «śmierć» («боль», «пустота», «тоска», «страх» и др.) и позволяющих выразить отношение к смерти либо ее оценку.

Представителями польской лингвокультуры смерть чаще всего оценивается негативно, что выражается в ассоциациях с черным цветом, холодом, запустением, грустной музыкой и т. д., при этом в анализируемых ассоциативных рядах совсем не встречаются, например, оценочные прилагательные или наречия (типа dobra - marna, zla, dobrze - źle и под.), т. е. прямая оценка, при наличии описательной, отсутствует.

Индивидуальные ассоциации, репрезентирующие личностный опыт осмысления смерти, разнообразны: от вполне традиционных (wieczny spokój, podsumowanie życia) до очень неожиданных (śmietana).

Весь спектр полученных ассоциаций позволяет говорить не только об особенностях структуры польского концепта «śmierć» (его признаках), но и о специфике концептуальных связей в сознании представителей польской лингвокультуры. Можно было предположить, что смерть, являясь конечной точкой существования, неразрывно в сознании человека связывается с жизнью (что отражается на системно-языковом уровне в виде антонимической пары śmierć - życie), однако ни один из участников эксперимента и опроса в свой ассоциативный ряд не включил собственно лексему «żусіе»/〈жизнь» (за исключением ее употребления в сочетаниях типа nowe życie, koniec życia и под.). Низкая частотность в ассоциативных рядах отмечена и у стилистически маркированных синонимов лексемы śmierć, фиксируемых словарями. В ассоциативных рядах отсутствуют фразеологизмы с лексемой «śmierć», которых в польском языке немало (znaleźć śmierć, patrzeć śmierci w oczy, grać ze śmiercia, blok śmierci и др.). Следовательно, бытование концепта «śmierć» в сознании носителей польского языка в большей степени определятся не языковыми связями единиц, репрезентирующими данный концепт, а экстралингвистическими факторами.

\section{Список литературы}

1. Карасик В. И. Символические концепты // Изменяющаяся Россия и славянский мир: новое в концептуальных исследованиях / отв. ред. М. В. Пименова. Вып. 11. Севастополь: Рибэст, 2009. С. 23-30.

2. Słownik synonimów i antonimów / red. M. Pawlus. Kraków: Drukarnia Narodowa, 2002. $484 \mathrm{~s}$.

3. Wielki słownik języka polskiego. URL: http://www.wsjp.pl/ (дата обращения: 20.06.2015).

4. Ожегов С. И., Шведова Н. Ю. Толковый словарь современного русского языка. М.: Азъ, 1995. 928 с.

5. Деева Н. В. Метафорическая репрезентация концептов «смерть» и «śmierć» в русской и польской лингвокультурах // Вестник РГУ им. С. А. Есенина. 2016. № 4/53. С. 120-127.

6. Абрамова Е. С. Ассоциативно-смысловое поле концепта // Apriori: электронный научный журнал. Серия «Гуманитарные науки». 2014. № 1. URL: http://www.apriori-journal.ru/journal-gumanitarnie-nauki/id/147 (дата обращения: 12.03.2017). 
7. Ogrodowska B. Polskie tradycje i obyczaje rodzinne. Warszawa: Muza SA, 2011. $323 \mathrm{~s}$.

8. Новиков В. М., Попов Е. В. Природа человека и смысл его существования // Основы философии. М.: ВЛАДОС, 1997. С. 72-101.

9. Славянские древности / под общ. ред. Н. И. Толстого. Т. 2. М.: Международные отношения, 1999. 697 с.

10. Символы и их значения: от наскальной живописи до модерна. URL: http://simvolic.ru/ankh/ (дата обращения: 1.07.2017).

11. Ручина Л. И. Ассоциативный эксперимент как инструмент выявления когнитивных признаков концепта // Вестник Нижегородского ун-та им. Н. И. Лобачевского. 2012. № 5-3. С. 102-106.

12. Кошеренкова О. В. Символика цвета в культуре // Аналитика культурологии. 2015. № 2 (32). С. 163-169.

13. Левкиевская Е. Е. Мифы русского народа. М.: АСТ: Астрель, 2000.528 с.

Деева Наталья Валерьевна, кандидат филологических наук, доцент, Кемеровский государственный институт культуры (ул. Ворошилова, 17, Кемерово, Россия, 650056). E-mail: deeva24@list.ru

Материал поступил в редакциюю 23.08.2017.

\author{
DOI 10.23951/1609-624X-2017-11-104-109
}

\title{
ASSOCIATE CONNECTIONS OF THE CONCEPT "ŚMIERĆ"
}

\section{N. V. Deeva}

\author{
Kemerovo State Institute of Culture, Kemerovo, Russian Federation
}

The article deals with the results of the experiment and the interview which were directed at revealing the associative links of the Polish concept "śmierć" / "death". A study of such kind of links can help in modeling the structure of the concept. The resulting verbal associations reflect the conceptual signs of the concept "śmierć" ("end', 'departure'), indicate a deep rootedness in the consciousness of the Poles of cultural stereotypes which are a figurative representation of death (in the image of a woman with a scythe, skeleton). Words that call objects, realities connected with the rite of the burial (cemetery, funeral, etc.) are few in the associative line.

The attitude toward death, its evaluation are found in the words-reactions, which call the feelings or conditions that a person experiences when faced with death. Most often these are heavy, unpleasant feelings or conditions (yearning, sadness, fear, etc.). Negative attitude towards death is represented in its associations with cold, darkness, ruins, etc.

Individual associations which represent the personal experience of understanding death are diverse: from completely traditional (wieczny spokój / eternal peace) to very unexpected (śmietana / sour cream).

The full spectrum of obtained associations allows to speak not only about the peculiarities of the structure of Polish concept "śmierć" (its signs), but also about the specifics of the conceptual connections in the consciousness of Polish-speakers.

Key words: concept, representation of concept, verbal associations, Polish linguoculture.

\section{References}

1. Karasik V. I. Simvolicheskiye kontsepty [Symbolic concepts]. Izmenyayushchayasya Rossiya i slavyanskiy mir: novoye v kontseptual'nykh issledovaniyakh. Vyp. 11 [Changing Russia and the Slavic World: New in Conceptual Studies. Vol. 11]. Ed. M. V. Pimenova. Sevastopol, Ribest Publ., 2009, pp. 23-30 (in Russian).

2. Słownik synonimów i antonimów. Red. M. Pawlus. Kraków, Drukarnia Narodowa, 2002. 484 p.

3. Wielki słownik języka polskiego. URL: http://www.wsjp.pl/ (accessed 20 June 2015).

4. Ozhegov S. I., Shvedova N. Yu. Tolkovyy slovar' sovremennogo russkogo yazyka [Explanatory dictionary of the modern Russian language]. Moscow, Az Publ., 1995. 928 p. (in Russian).

5. Deeva N. V. Metaforicheskaya reprezentatsiya kontseptov "smert"' i “śmierć" v russkoy i pol'skoy lingvokul'turakh [The metaphorical representation of the concepts "death" and "śmierć" in Russian and Polish linguocultures]. Vestnik Ryazanskogo gosudarstvennogo universiteta im. S. A. Esenina - Bulletin of Ryazan State University named after S. A. Yesenin, 2016, no. 4/53, pp. 120-127 (in Russian).

6. Abramova E. S. Assotsiativno-smyslovoye pole kontsepta [Associative and semantic field of the concept]. Apriori: elektronnyy nauchnyy zhurnal. Ser. "Gumanitarnye nauki" - Apriori: electronic scientific journal. Series Humanities, 2014, no. 1 (in Russian). URL: http://www.apriori-journal.ru/ journal-gumanitarnie-nauki/id/147 (accessed 12 March 2017).

7. Ogrodowska B. Polskie tradycje i obyczaje rodzinne. Warszawa, Muza SA, 2011. 323 p.

8. Novikov V. M., Popov E. V. Priroda cheloveka i smysl ego sushchestvovaniya [The nature of man and the meaning of his existence]. Osnovy filosofii [Basics of Philosophy]. Moscow, VLADOS, 1997. Pp. 72-101 (in Russian).

9. Slavyanskiye drevnosti [Slavic antiquities]. Under the general ed. N. I. Tolstoy, vol. 2, Moscow, International Relations, 1999. 697 p. (in Russian). 
10. Simvoly i ikh znacheniya: ot naskal'noy zhivopisi do moderna [Symbols and their meanings: from rock art to modern art] (in Russian). URL: http:/l simvolic.ru/ankh/ (accessed 1 July 2017).

11. Ruchina L. I. Assotsiativnyy eksperiment kak instrument vyyavleniya kognitivnykh priznakov kontsepta [Associative experiment as a tool for revealing the cognitive features of the concept]. Vestnik Nizhegorodskogo universiteta im. N. I. Lobachevskogo - Bulletin of Nizhny Novgorod University named after N. I. Lobachevski, 2012, no. 5-3, pp. 102-106 (in Russian).

12. Kosherenkova O. V. Simvolika tsveta v kul'ture [Symbolism of color in culture]. Analitika kul'turologii - Analytics of culturology, 2015, no. 2 (32), pp. 163-169 (in Russian).

13. Levkievskaya E. E. Mify russkogo naroda [Myths of the Russian people]. Moscow, AST, Astrel Publ., 2000. 528 p. (in Russian).

Deeva N. V., Kemerovo State Institute of Culture (ul. Voroshilova, 17, Kemerovo, Russian Federation, 650056).

E-mail: deeva24@list.ru 